\title{
ALTERATIONS IN LIVER ACTIVITY AND LIVER FUNCTIONALITY INDEXES DURING POST - PARTUM PERIOD IN EGYPTIAN BUFFALOES
}

\author{
HANAN K. ELSAYED ${ }^{1}$; EMAN M. ABD- ELNASER ${ }^{2}$; AHMED ABDEL-FATTAH AAMER ${ }^{1}$ and \\ SALLY ABD ELSAYED ALIY ${ }^{2}$ \\ ${ }^{1}$ Dept. of Animal Medicine, Faculty of Veterinary Medicine, Assiut University, Assiut, Egypt. \\ ${ }^{2}$ Animal Health Research Institute, Assiut Branch
}

Received: 31 December 2018; Accepted: 31 January 2019

\begin{abstract}
The objective of this study was to calculate the liver activity index (LAI) and the liver functionality index (LFI) in buffaloes during post- partum period., 29 pregnant buffaloes were selected at $2^{\text {nd }}$ and $3^{\text {rd }}$ milk season from Ard El -Kheir farm in Assuit Governorate. Blood plasma was collected for determination of vit. A and serum were collected for determination of serum albumin, total cholesterol and total bilirubin. Samples were collected as the following: (-21d: -15d), (-14d: -8d), (-7d: -1d), calving day, 3 d P.P, 7 d P.P, 14 d P.P and 28 d P.P. After calculation of indexes, animals were classified into high and low groups (whenever the result is positive, it is considered high and whenever the result is negative, it is considered low). The study revealed highly significant difference in the mean values between high and low groups. The mean values of albumin revealed a non significant decrease in serum albumin in the low group compared with the high one at the same period in both indexes, except in LAI at calving day; there was a significant decrease in (LLAI) group compared with the (HLAI) one. Non significant decrease in the mean values of serum total cholesterol in the low group compared with the high one at the same period in both indexes, except in LAI at day 28 P.P.; there was a significant decrease in the (LLAI) group compared with the (HLAI) one. Non significant decrease in the mean values of vit. A in the (LLAI) group compared with the (HLAI) one at the same period except at day 14 P.P, there was a significant decrease in the (LLAI) group compared with the (HLAI) one. The mean values of total bilirubin revealed highly significant difference between the (HLFI) and the (LLFI) groups during period of the study. A significant increase in total bilirubin at day 3 P.P in the (LLFI) group compared with the (HLFI) one and a significant increase $(\mathrm{p}<0.05)$ in the $(\mathrm{HLFI})$ at days 14 and day 28 P.P compared with the (LLFI).
\end{abstract}

Key words: Acute phase proteins, liver activity index, liver functionality index, buffaloes, Assuit, albumin, total cholesterol, total bilirubin, vit. A

\section{INTRODUCTION}

Acute phase proteins (APPs) are blood proteins primarily synthesized by hepatocytes as part of the acute phase response. The acute phase response is a non-specific complex reaction of an organism, triggered by different stimuli (Cray et al., 2009). The APPs consist of negative and positive proteins that show a decrease and an increase in levels, respectively, in response to challenge or stressors (Eckersall, 2004, Murata et al., 2004 and Gruys et al., 2005).

Negative acute phase proteins (-APPs) seem appropriate indices to detect consequences of an

Corresponding author: HANAN K. ELSAYED

E-mail address: hanankama1726@yahoo.com

Present address: Dept. of Animal Medicine, Faculty of Veterinary Medicine, Assiut University, Assiut, Egypt. inflammatory condition in the peripartum period. In fact, changes of -APP are prolonged in comparison to the rise of positive acute phase protein (+APP). The association between +APP response after calving and acute inflammatory phenomena is not always very clear and marked. Therefore, two composed indices based on levels of some -APP observed in the first month of lactation, with the aim to evaluate the changes on liver activity synthesis caused by inflammatory events occurred around caving: the Liver Activity Index (LAI) (Trevisi et al., 2001) and the Liver Functionality Index (LFI) (Bertoni et al., 2006).

LAI includes the average blood level at $7^{\text {th }}, 14^{\text {th }}$ and $28^{\text {th }}$ DIM of some proteins synthesized by the liver: albumin, lipoproteins (indirectly measured as total cholesterol), and Retinol binding Protein (RBP, measured as retinol, as the retinol released from the 
liver depends mainly on the synthesis of apo-RBP. The mean value of the herd population of each blood parameter (albumin, total cholesterol and RBP) was subtracted from each cow value at 7,14 , and 28 DIM and divided by the corresponding standard deviation. The final LAI of each cow is the result of the arithmetical mean of the 3 partial values obtained from the 3 selected blood indices of 3 blood samples (Trevisi et al., 2001). This index that varies between -1.5 and +1.5 points can provide a good evaluation of inflammatory phenomena and their consequences, as demonstrated by Trevisi et al. (2005) and Trevisi et al. (2010).

LFI is an index of the relevant changes between DIM 3 (V3) and 28 (V28), standardized in accordance with the optimal pattern of changes of the 3 parameters, obtained from healthy cows at the same stage of lactation.

For each parameter, LFI calculation is done in 2 steps (Bertoni et al., 2006 and Trevisi et al., 2011). The $1^{\text {st }}$ one considers the effects occurred at $3^{\text {rd }}$ DIM (V3) and changes between $3^{\text {rd }}$ and $28^{\text {th }}$ (V28) DIM. For albumin and cholesterol these two effects equally concur (50\%) to the partial LFI result (Alb-I and Chol-I), while for bilirubin the effect at DIM 3 represents $67 \%$ of the total partial LFI index.

In the $2^{\text {nd }}$ step, these partial indices were standardized in accordance with the average values observed in "healthy" cows. It is interesting that the two indices are well correlated (Trevisi et al., 2010b).

The LFI varies between -12 and +5 points Values above zero are considered favorable (Bertoni and Trevisi, 2013).

To the best of our knowledge, studies on liver activity index and liver functionality index in buffaloes are scarce. So, the main objective of this study was to calculate the liver activity index (LAI) and the liver functionality index (LFI) in buffaloes during post- partum period.

\section{MATERIALS AND METHODS}

\section{1- Animals:}

The study was carried out on 29 healthy, multiparous buffaloes at transition period (3weeks before calving and 4 weeks after calving), with average age of 2-4 years old from a private farm belongs to Assuit Governorate (Ard El- Kheir). Samples were collected during summer season. Buffaloes were fed daily on meal composed of corn, soybeans, wheat bran, silage, little amount of sunflower, hay, multi vitamins, mineral mixture, antioxidant, buffer, dibasic phosphate" only before calving"). Protein in ration usually $11 \%$, but at dry period reach 14- 16\%. Water was supplied ad libitum.

\section{2- Samples:}

Blood samples were collected in early morning; avoid stress or physical efforts as possible, avoid sick buffaloes, samples were kept in ice box and centrifuged within $2 \mathrm{~h}$ of collection. Three blood samples were collected by jugular vein puncture in vacuum tubes (Vacuette, Greiner Austria) containing no anti-coagulant, or lithium-heparin, or K3EDTA.

Several blood samples were collected from each animal before calving, according to calving day, only samples at the (- 21:-15) days, (-14: -8) days, $(-7:-1)$ days were used, then at calving day, $3^{\text {rd }}, 7^{\text {th }}$, $14^{\text {th }}$ and $28^{\text {th }}$ days post calving.

\section{LFI}

Step 1:

Albumin (Alb-I) sub-index $=50 \%$ V3 $+50 \%$ (V28V3)

Cholesterol (Chol-I) sub-index $=50 \% \mathrm{~V} 3+50 \%$ (V28-V3)

Bilirubin $($ Bil-I) sub-index $=67 \% \mathrm{~V} 3+33 \%(\mathrm{~V} 3-$ V28)

\section{Step 2:}

$\mathrm{LFI}=($ Alb-I -17.71$) / 1.08+($ Chol-I -2.57$) / 0.43-$ (Bil-I - 6.08) /2.17

\section{3- Clinical examination:}

All animals in the study were subjected to general clinical examination, where the clinical examination including body temperature, respiratory and pulse rates, ruminal movement, visual inspection of the udder, appetite as well as examination of mucous membranes were conducted according to Rosenberger (1990).

\section{Biochemical analysis:}

Measurement of vit. A chemically by spectrophotometric method (Carr and Price, 1926). Measurements of albumin, total cholesterol and total bilirubin by using commercial test kits supplied by diamond diagnostics (diamond diagnostics, Egyptian company for biotechnology) measured spectrophotometry using Optizen 3220 UV spectrophotometer. Spectrophotometeric assay was performed using spectrophotometer in the department of Animal Medicine- Faculty of Veterinary Medicine, Assiut University, Assuit Egypt. 


\section{Statistical analysis:}

Values are presented as means \pm standard error of the mean (SEM). Results of LAI \&LFI were classified into high and low groups. The unpaired student " $t$ " test was performed in graph prism version 5 to determine the significance of difference between group's means.

Statistical analysis of obtained data was carried out using general linear model (GLM procedure) of SAS System (2004). Two-way analysis of variance (ANOVA) with repeated measurements was carried out to study the effect of periods, groups and the interaction between them. The statistical significance of difference between period's means and means of interaction between periods \& groups were determined using Duncan's Multiple Range Test (DMRT) (Steel and Torrie, 1980). All the variables were considered significant at $(\mathrm{p}<0.05)$.

\section{RESULTS}

Results of Liver functionality index (LFI) and Liver activity index (LAI) are illustrated in Table (1). Mean values of calculated values revealed high significant $(\mathrm{p}<0.01)$ increase in the high group compared with the low one.

Results of measured blood parameters used in calculation of liver activity index are illustrated in Table (2, 3 and 4) and Figure (1, 2 and 3):
Mean values revealed a non significant decrease in serum albumin in the (LLAI) group compared with the (HLAI) one at the same period except at calving day there was a significant $(\mathrm{p}<0.05)$ decrease in (LLAI) group compared with the (HLAI) one, a non significant decrease in serum total cholesterol in the (LLAI) group compared with the (HLAI) one at the same period except at day 28 P.P, there was a significant $(p<0.05)$ decrease in the (LLAI) group compared with the (HLAI) one and a non significant decrease in vit. A in the (LLAI) group compared with the (HLAI) one except at day 14 P.P, there was a significant decrease $(p<0.05)$ in the $($ LLAI) group compared with the (HLAI) one.

Results of measured blood parameters used in calculation of liver functionality index are illustrated in Table (5, 6 and 7) and Figure (4, 5 and $6)$ :

Mean values revealed a non significant decrease in serum albumin in the (LLFI) group compared with the (HLFI) one at the same period, a non significant decrease in serum total cholesterol in the (LLFI) group compared with the (HLFI) one during the same period and highly significant $(\mathrm{p}<0.01)$ difference in serum total bilirubin between the (HLFI) and the (LLFI) groups during period of the study. A significant increase $(\mathrm{p}<0.05)$ at day 3 P.P in the (LLFI) group compared with the (HLFI) one and a significant increase $(\mathrm{p}<0.05)$ in the $(\mathrm{HLFI})$ during day 14 and day 28 P.P compared with the (LLFI) at the same periods.

Table 1: Mean values \pm SE of Liver activity index and liver functionality index in studied animals:

\begin{tabular}{|c|c|c|c|c|}
\hline & HLAI & LLAI & HLFI & LLFI \\
\hline No of animals & 16 & 13 & 16 & 13 \\
\hline Range & $(0.01: 0.78)$ & $(-0.39:-0.01)$ & $(0.25: 6.12)$ & $(-5.13:-0.03)$ \\
\hline Mean \pm SE & $(0.25 \pm 0.05)$ & $(-0.13 \pm 0.04)$ & $(3.35 \pm 0.53)$ & $(-1.54 \pm 0.40)$ \\
\hline$P$ value & \multicolumn{2}{|c|}{$<0.0001$} & \multicolumn{2}{|c|}{$<0.0001$} \\
\hline
\end{tabular}

HLAI: High liver activity index, LLAI: Low liver activity index, HLFI: High liver functionality index, LLFI: Low liver functionality index. 
Table 2: Mean values of serum albumin in high and low liver activity index groups during periparturient period.

\begin{tabular}{|c|c|c|c|c|c|c|}
\hline \multirow[b]{2}{*}{ Parameter } & \multirow[b]{2}{*}{$\begin{array}{l}\text { Days relat } \\
\text { to calving }\end{array}$} & \multirow[b]{2}{*}{$\begin{array}{l}\text { HLAI } \\
\mathrm{N}=16\end{array}$} & \multirow[b]{2}{*}{$\begin{array}{l}\text { LLAI } \\
\mathbf{N}=13\end{array}$} & \multicolumn{3}{|c|}{$\begin{array}{c}\text { Repeated measures analysis of } \\
\text { variance }\end{array}$} \\
\hline & & & & $\begin{array}{c}\text { Index } \\
\text { (P value) }\end{array}$ & $\begin{array}{l}\text { Time } \\
\text { (P value) }\end{array}$ & $\begin{array}{c}\text { Time } \\
\mathbf{X} \\
\text { Index } \\
\text { (P value) }\end{array}$ \\
\hline \multirow{8}{*}{$\begin{array}{l}\text { Albumin } \\
(\mathrm{g} / \mathrm{l})\end{array}$} & $\begin{array}{c}(-21 d:-15 d) \\
\text { a.p }\end{array}$ & $43.02 \pm 1.19^{\mathbf{c}, 3}$ & $41.90 \pm 0.71^{\mathbf{c}, 3}$ & $0.0203^{*}$ & $<0.0001^{* *}$ & 0.8627 \\
\hline & $\begin{array}{l}(-14 d:-8 d) \\
\text { a.p }\end{array}$ & $42.88 \pm 0.76^{\mathbf{c}, 3}$ & $42.52 \pm 0.81^{\mathbf{c}, 3}$ & & & NS \\
\hline & $\begin{array}{l}(-7 d:-1 d) \\
\text { a.p }\end{array}$ & $49.33 \pm 2.02^{\mathbf{a}, \mathbf{1}}$ & $49.38 \pm 1.48^{\mathrm{a}, \mathbf{1}}$ & & & \\
\hline & Calving day & $48.61 \pm 1.66^{\mathbf{a b}, \mathbf{1}, 2}$ & $44.51 \pm 2.08^{\mathbf{c}, 3}$ & & & \\
\hline & 3 d p.p & $45.24 \pm 1.23^{\mathbf{b c}, \mathbf{2}, 3}$ & $43.93 \pm 1.16^{\mathbf{c}, 3}$ & & & \\
\hline & 7 d p.p & $44.70 \pm 1.57^{\mathbf{b c}, \mathbf{2}, \mathbf{3}}$ & $42.27 \pm 1.24^{\mathbf{c}, 3}$ & & & \\
\hline & $14 \mathrm{~d}$ p.p & $44.14 \pm 0.95^{\mathrm{c}, 3}$ & $42.68 \pm 1.23$ & & & \\
\hline & $28 \mathrm{~d}$ p.p & $43.84 \pm 1.03^{c, 3}$ & $42.03 \pm 0.89^{\mathbf{c}, 3}$ & & & \\
\hline
\end{tabular}

Values $=$ mean \pm standard error; means of different superscript letters in the same column differ significantly $(\mathrm{p}<0.05)$. Means of different arabic letters in the same row differ significantly $(\mathrm{p}<0.05)$. a.p, ante partum; $\mathbf{d}$ p.p, day post partum; N, number; HLAI, high liver activity index, LLAI, low liver activity index; ${ }^{*}$ significant at $(\mathrm{p}<0.05) ;{ }^{* *}$ significant at $(\mathrm{p}<0.01) ; \mathbf{N S}$, non significant.

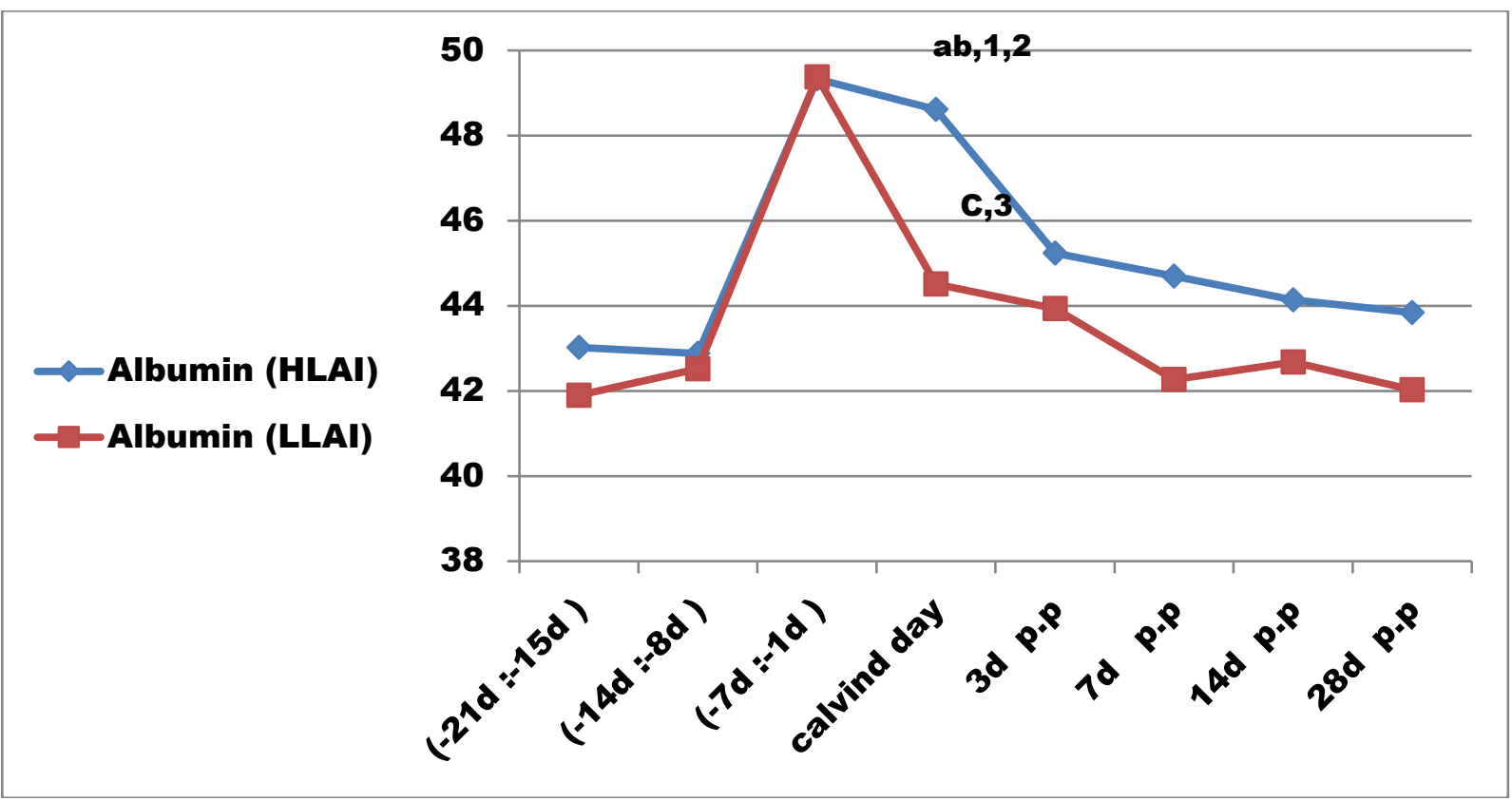

Figure 1: Serum albumin concentrations in High and Low liver activity index (LAI) groups during periparturient period. 
Table 3: Mean values of serum total cholesterol in high and low liver activity index groups during periparturient period.

\begin{tabular}{|c|c|c|c|c|c|c|}
\hline \multirow[b]{2}{*}{ Parameter } & \multirow[b]{2}{*}{$\begin{array}{r}\text { Days relativ } \\
\text { to calving }\end{array}$} & \multirow[b]{2}{*}{$\begin{array}{l}\text { HLAI } \\
\mathrm{N}=16\end{array}$} & \multirow[b]{2}{*}{$\begin{array}{l}\text { LLAI } \\
\mathbf{N}=13\end{array}$} & \multicolumn{3}{|c|}{$\begin{array}{c}\text { Repeated measures analysis of } \\
\text { variance }\end{array}$} \\
\hline & & & & $\begin{array}{c}\text { Index } \\
\text { (P value) }\end{array}$ & $\begin{array}{c}\text { Time } \\
\text { (P value) }\end{array}$ & $\begin{array}{c}\text { Time } \\
\mathbf{X} \\
\text { Index } \\
\text { (P value) }\end{array}$ \\
\hline \multirow{8}{*}{$\begin{array}{c}\text { Total } \\
\text { cholesterol } \\
(\mathrm{mmol} / \mathrm{l})\end{array}$} & $\begin{array}{c}(-21 d:-15 d) \\
\text { a.p }\end{array}$ & $1.43 \pm 0.08$ & $1.50 \pm 0.04^{\mathbf{c}, 3}$ & $0.0367^{*}$ & $<0.0001^{* *}$ & 0.575 \\
\hline & $\begin{array}{l}(-14 d:-8 d) \\
\text { a.p }\end{array}$ & $1.40 \pm 0.04^{\mathbf{c d}, \mathbf{3}, 4}$ & $1.40 \pm 0.06^{\text {cd,3,4 }}$ & & & NS \\
\hline & $\begin{array}{l}(-7 d:-1 d) \\
\text { a.p }\end{array}$ & $1.20 \pm 0.04^{\text {def }, \mathbf{4 , 5}, \mathbf{6}}$ & $1.16 \pm 0.05^{\text {ef,5,6 }}$ & & & \\
\hline & Calving day & $0.85 \pm 0.05^{\text {gh, }, \mathbf{7}, \mathbf{8}}$ & $0.77 \pm 0.05^{\mathbf{h}, \mathbf{8}}$ & & & \\
\hline & 3 d p.p & $1.08 \pm 0.05^{\mathbf{f}, 6}$ & $1.03 \pm 0.06 \mathrm{fg}, 6,7$ & & & \\
\hline & 7 d p.p & $1.14 \pm 0.06^{\text {ef,5,6 }}$ & $1.01 \pm 0.07 \mathrm{fg}, 6,7$ & & & \\
\hline & 14 d p.p & $1.48 \pm 0.11^{\mathbf{c}, 3}$ & $1.36 \pm 0.07^{\text {cde, } \mathbf{3 , 4 , 5}}$ & & & \\
\hline & 28 d p.p & $1.96 \pm 0.12^{\mathrm{a}, \mathbf{1}}$ & $1.72 \pm 0.09 \quad \mathbf{b}, \mathbf{2}$ & & & \\
\hline
\end{tabular}

Values $=$ mean \pm standard error; means of different superscript letters in the same column differ significantly $(p<0.05)$. Means of different arabic letters in the same row differ significantly $(p<0.05)$. a.p, ante partum; d p.p, day post partum; N, number; HLAI, high liver activity index; LLAI, low liver activity index; ${ }^{*}$ significant at $(\mathrm{p}<0.05) ;{ }^{* *}$ significant at $(\mathrm{p}<0.01) ; \mathbf{N S}$, non significant

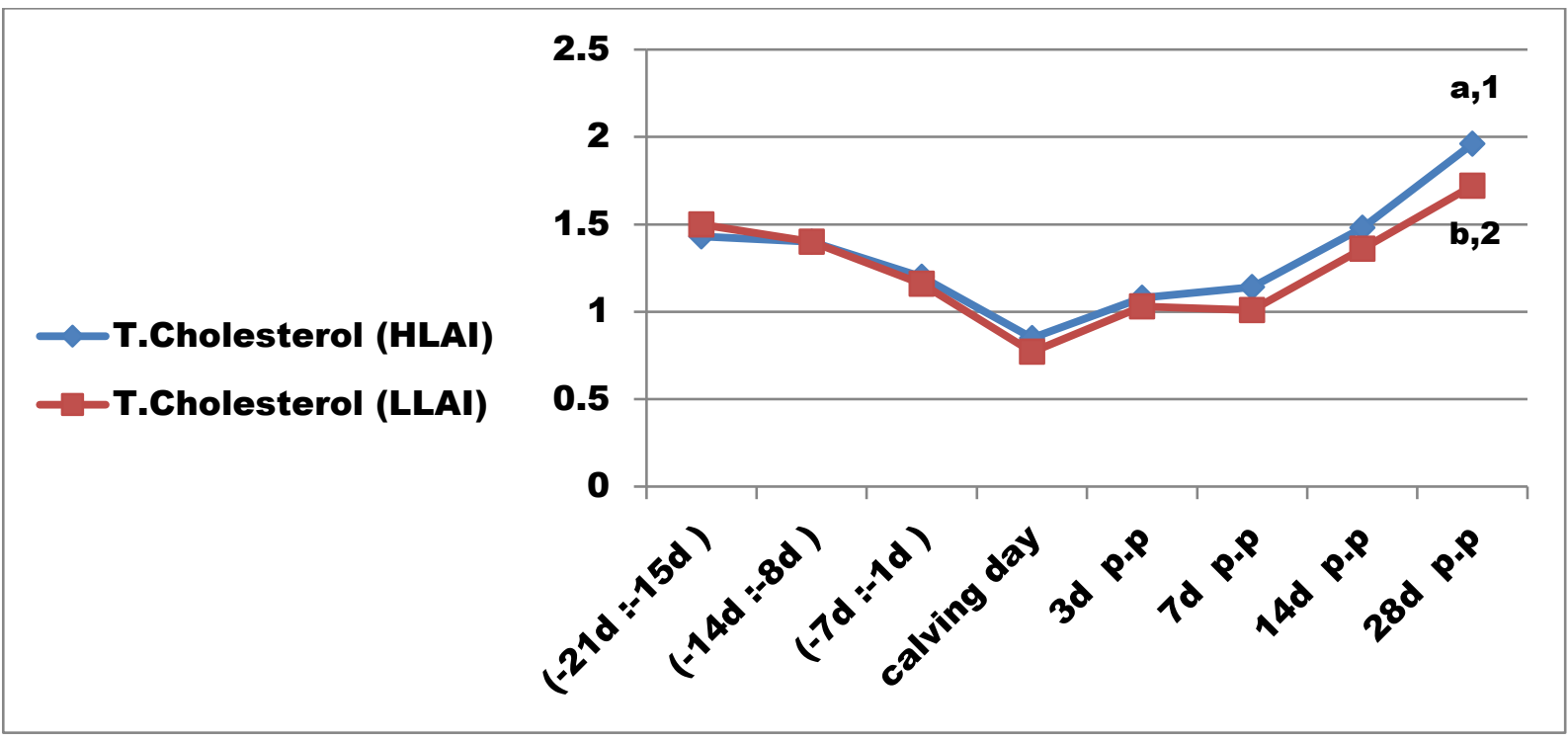

Figure 2: Serum total cholesterol concentrations in High and Low liver activity index (LAI) groups during periparturient period. 
Table 4: Mean values of serum vit. A in High and Low liver activity index groups during periparturient period.

\begin{tabular}{|c|c|c|c|c|c|c|}
\hline \multirow[b]{2}{*}{ Parameter } & \multirow[b]{2}{*}{$\begin{array}{l}\text { relative } \\
\text { to calving }\end{array}$} & \multirow[b]{2}{*}{$\begin{array}{l}\text { HLAI } \\
\mathrm{N}=16\end{array}$} & \multirow[b]{2}{*}{$\begin{array}{l}\text { LLAI } \\
\mathbf{N}=13\end{array}$} & \multicolumn{3}{|c|}{$\begin{array}{c}\text { Repeated measures analysis of } \\
\text { variance }\end{array}$} \\
\hline & & & & $\begin{array}{c}\text { Index } \\
\text { (P value) }\end{array}$ & $\begin{array}{c}\text { Time } \\
\text { (P value) }\end{array}$ & $\begin{array}{c}\text { Time } \\
\text { X Index } \\
\text { (P value) }\end{array}$ \\
\hline \multirow{8}{*}{$\begin{array}{l}\text { Vit. A } \\
(\mu \mathrm{g} / \mathrm{dl})\end{array}$} & $\begin{array}{c}(-21 d:-15 d) \\
\text { a.p }\end{array}$ & $50.40 \pm 0.98^{\mathbf{a b}, \mathbf{1}, \mathbf{2}}$ & $49.38 \pm 0.95^{\mathbf{b c}, \mathbf{2}, \mathbf{3}}$ & \multirow[t]{8}{*}{$0.0012^{* *}$} & \multirow[t]{8}{*}{$<0.0001^{* *}$} & \multirow{8}{*}{$\begin{array}{c}0.877 \\
\mathrm{NS}\end{array}$} \\
\hline & $\begin{array}{c}\text { (-14d:-8d) } \\
\text { a.p }\end{array}$ & $47.44 \pm 0.90^{\text {bcd, } \mathbf{2 , 3}, \mathbf{4}}$ & $46.56 \pm 1.11^{\text {cde }, \mathbf{3}, \mathbf{4 , 5}}$ & & & \\
\hline & $\begin{array}{c}(-7 d:-1 d) \\
\text { a.p }\end{array}$ & $45.46 \pm 0.80^{\text {de, } \mathbf{4}, \mathbf{5}}$ & $44.61 \pm 0.96^{\mathrm{de}, \mathbf{4}, \mathbf{5}}$ & & & \\
\hline & Calving day & $40.26 \pm 0.87^{\mathbf{f}, 6}$ & $39.21 \pm 1.06^{\mathbf{f , 6}}$ & & & \\
\hline & 3 d P.P & $37.64 \pm 0.98^{\mathrm{fg}, 6,7}$ & $35.84 \pm 1.13^{\mathbf{g h}, 7,8}$ & & & \\
\hline & 7 d P.P. & $35.21 \pm 0.90^{\mathbf{g h ,}, \mathbf{7 , 8}}$ & $33.48 \pm 1.12 \quad \mathbf{h}, 8$ & & & \\
\hline & 14d P.P. & $47.17 \pm 1.10^{\text {bcd,2,3,4 }}$ & $43.82 \pm 1.28$ e,5 & & & \\
\hline & 28 d P.P. & $53.38 \pm 1.14^{\text {a, } 1}$ & $50.38 \pm 1.34^{\mathbf{a b}, \mathbf{1}, \mathbf{2}}$ & & & \\
\hline
\end{tabular}

Values $=$ mean \pm standard error; means of different superscript letters in the same column differ significantly $(\mathrm{p}<0.05)$. Means of different arabic letters in the same row differ significantly $(\mathrm{p}<0.05)$. a.p, ante partum; d P.P, day post partum; N, number; HLAI, high liver activity index; LLAI, low liver activity index; ${ }^{* *}$ significant at $(\mathrm{p}<0.01)$; NS, non significant.

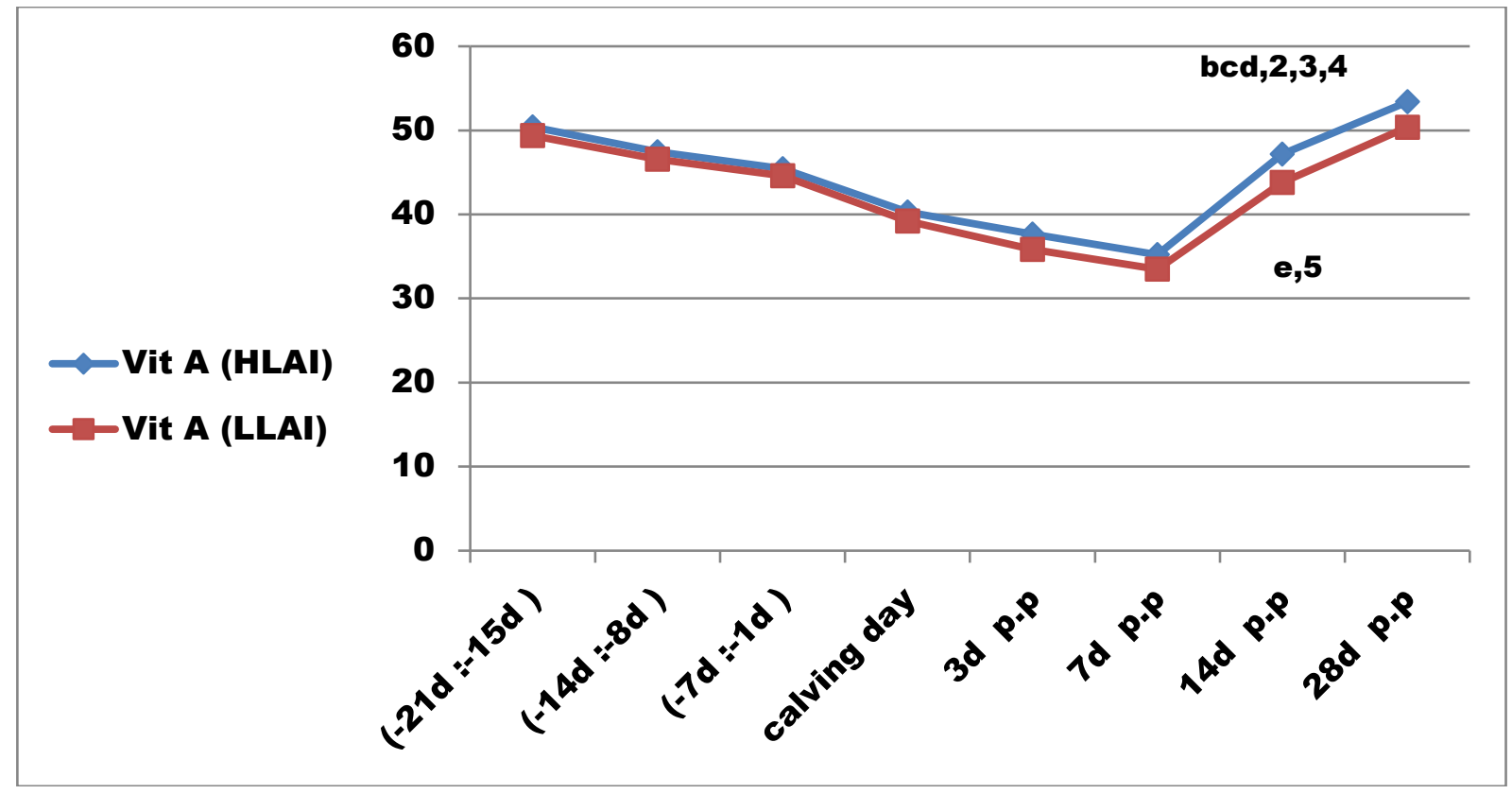

Figure 3: Serum vit. A concentrations in High and Low liver activity index (LAI) groups during periparturient period. 
Table 5: Mean values of serum albumin in High and Low liver functionality index groups during periparturient period.

\begin{tabular}{|c|c|c|c|c|c|c|}
\hline \multirow[b]{2}{*}{ Parameter } & \multirow{2}{*}{$\begin{array}{l}\text { Group } \\
\text { Days } \\
\text { relative } \\
\text { to calving }\end{array}$} & \multirow[b]{2}{*}{$\begin{array}{l}\text { HLFI } \\
\mathrm{N}=16\end{array}$} & \multirow[b]{2}{*}{$\begin{array}{l}\text { LLFI } \\
\mathbf{N}=13\end{array}$} & \multicolumn{3}{|c|}{$\begin{array}{l}\text { Repeated measures analysis of } \\
\text { variance }\end{array}$} \\
\hline & & & & $\begin{array}{c}\text { Index } \\
\text { (P value) }\end{array}$ & $\begin{array}{c}\text { Time } \\
\text { (P value) }\end{array}$ & $\begin{array}{c}\text { Time } \\
\mathbf{X} \\
\text { Index } \\
\text { (P value) }\end{array}$ \\
\hline \multirow{8}{*}{$\begin{array}{l}\text { Albumin } \\
\qquad(\mathrm{g} / \mathrm{l})\end{array}$} & $\begin{array}{c}(-21 d:-15 d) \\
\text { a.p }\end{array}$ & $42.91 \pm 1.13^{\mathbf{c d , 3 , 4}}$ & $42.08 \pm 0.86^{\text {cd,3,4 }}$ & \multirow[t]{8}{*}{$0.0027^{* *}$} & \multirow[t]{8}{*}{$<0.0001^{* *}$} & \multirow{8}{*}{$\begin{array}{r}0.906 \\
\mathrm{NS}\end{array}$} \\
\hline & $\begin{array}{l}(-14 d:-8 d) \\
\text { a.p }\end{array}$ & $42.79 \pm 0.71^{\text {cd, }, 3,4}$ & $42.64 \pm 0.88^{\text {cd,3,4 }}$ & & & \\
\hline & $\begin{array}{c}(-7 d:-1 d) \\
\text { a.p }\end{array}$ & $50.29 \pm 2.03^{\mathrm{a}, 1}$ & $48.20 \pm 1.38^{\mathbf{a b}, \mathbf{1}, \mathbf{2}}$ & & & \\
\hline & Calving day & $48.17 \pm 1.65^{\mathbf{a b}, \mathbf{1}, \mathbf{2}}$ & $45.05 \pm 2.17$ bcd,2,3,4 & & & \\
\hline & 3 d p.p. & $46.20 \pm 1.21^{\mathbf{b c}, \mathbf{2 , 3}}$ & $42.75 \pm 0.99^{\text {cd,3,4 }}$ & & & \\
\hline & 7 d p.p. & $44.16 \pm 1.49$ bcd,2,3,4 & $42.93 \pm 1.45^{\mathrm{cd}, \mathbf{3}, 4}$ & & & \\
\hline & 14 d p.p. & $44.46 \pm 1.02^{\text {bcd,2,3,4,4 }}$ & $42.28 \pm 1.08^{\text {cd,3,4 }}$ & & & \\
\hline & 28 d p.p. & $44.4 \pm 0.89$ bcd,2,3,4, & $41.35 \pm 0.97 \quad \mathbf{d}, \mathbf{4}$ & & & \\
\hline
\end{tabular}

Values $=$ mean \pm standard error; means of different superscript letters in the same column differ significantly $(p<0.05)$. Means of different arabic letters in the same row differ significantly $(p<0.05)$. a.p, ante partum; d p.p, day post partum; N, number; HLFI, high liver functionality index; LLFI, low liver functionality index; ${ }^{* *}$ significant at $(\mathrm{p}<0.01) ; \mathbf{N S}$, non significant

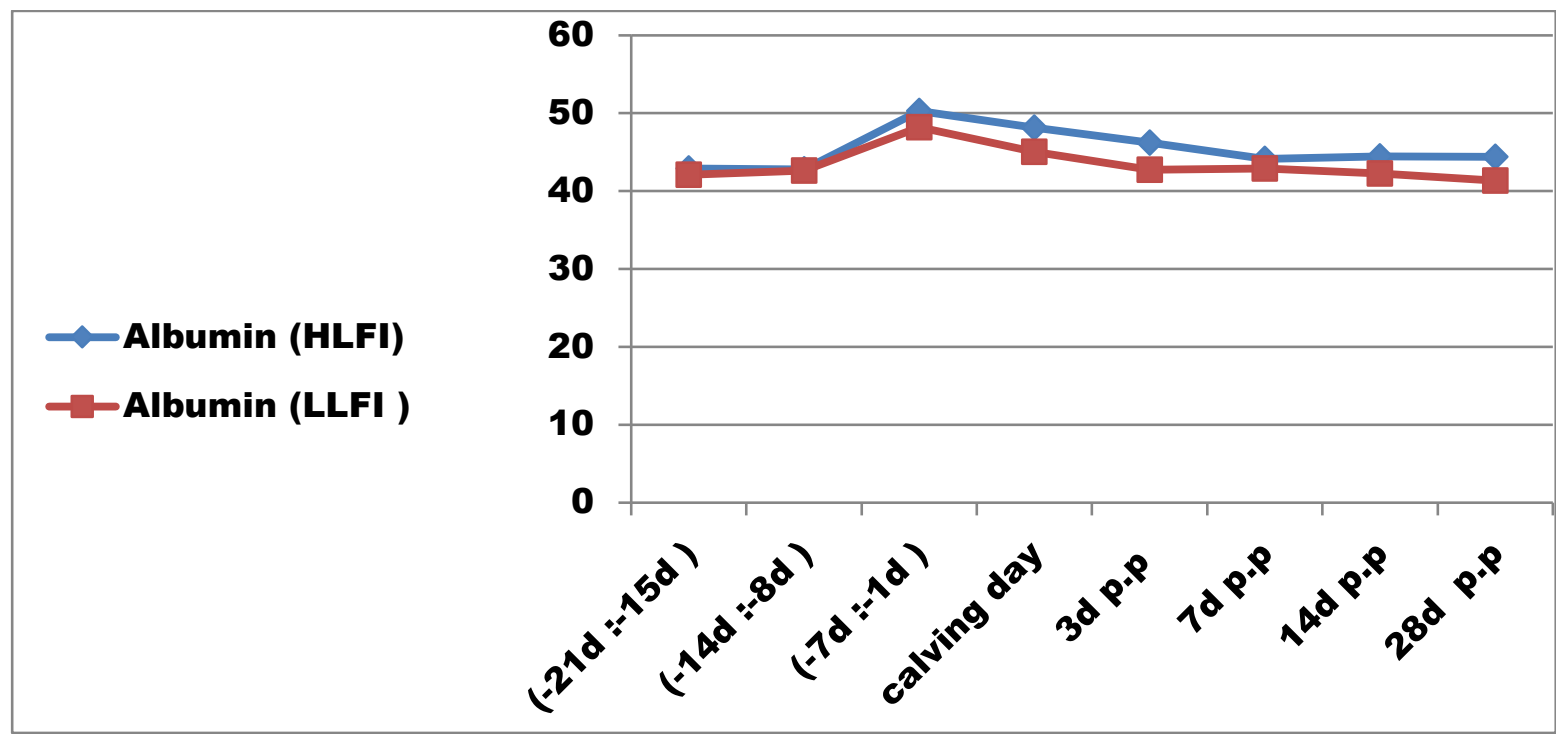

Figure 4: Serum albumin concentrations in High and Low liver functionality index (LFI) groups during periparturient period. 
Table 6: Mean values of serum total cholesterol in High and Low liver functionality index groups during periparturient period.

\begin{tabular}{|c|c|c|c|c|c|c|}
\hline \multirow[b]{2}{*}{ Parameter } & \multirow[t]{2}{*}{ Group } & \multirow[b]{2}{*}{$\begin{array}{l}\text { HLFI } \\
\mathrm{N}=16\end{array}$} & \multirow[b]{2}{*}{$\begin{array}{l}\text { LLFI } \\
N=13\end{array}$} & \multicolumn{3}{|c|}{$\begin{array}{c}\text { Repeated measures analysis of } \\
\text { variance }\end{array}$} \\
\hline & & & & $\begin{array}{c}\text { Index } \\
\text { (P value) }\end{array}$ & $\begin{array}{c}\text { Time } \\
\text { (P value) }\end{array}$ & $\begin{array}{c}\text { Time } \\
\mathbf{X} \\
\text { Index } \\
\text { (P value) }\end{array}$ \\
\hline \multirow{8}{*}{$\begin{array}{c}\text { Total } \\
\text { cholesterol } \\
(\mathbf{m m o l} / \mathbf{l})\end{array}$} & $\begin{array}{c}(-21 d:-15 d) \\
\text { a.p }\end{array}$ & $1.50 \pm 0.07 \quad \mathbf{b}, 2$ & $1.41 \pm 0.07$ bc, 2,3 & $\begin{array}{l}0.6356 \\
\text { NS }\end{array}$ & $<0.0001^{* *}$ & $\begin{array}{c}0.928 \\
\text { NS }\end{array}$ \\
\hline & $\begin{array}{l}(-14 d:-8 d) \\
\text { a.p }\end{array}$ & $1.37 \pm 0.04$ bcd, $2,3, \mathbf{3}$ & $1.44 \pm 0.05 \quad \mathbf{b}, 2$ & & & \\
\hline & $\begin{array}{c}(-7 d:-1 d) \\
\text { a.p }\end{array}$ & $1.16 \pm 0.04 \mathrm{de}, \mathbf{4 , 5}$ & $1.20 \pm 0.05^{\mathrm{cde}, 3,4,5}$ & & & \\
\hline & Calving day & $0.82 \pm 0.05^{\mathbf{f}, 6}$ & $0.81 \pm 0.06^{\mathbf{f}, \mathbf{6}}$ & & & \\
\hline & $3 \mathrm{~d}$ p.p & $1.06 \pm 0.05 \quad$ e, 5 & $1.05 \pm 0.07 \quad$ e,5 & & & \\
\hline & 7 d p.p. & $1.09 \pm 0.06^{\mathrm{e}, 5}$ & $1.07 \pm 0.06 \quad$ e, 5 & & & \\
\hline & 14 d p.p. & $1.42 \pm 0.10 \quad \mathbf{b c}, \mathbf{2 , 3}$ & $1.42 \pm 0.10^{\mathbf{b c}, 2,3}$ & & & \\
\hline & 28 d p.p. & $1.90 \pm 0.13^{\mathrm{a}, 1}$ & $1.79 \pm 0.08 \quad$ a,1 & & & \\
\hline
\end{tabular}

Values $=$ mean \pm standard error; means of different superscript letters in the same column differ significantly $(p<0.05)$. Means of different arabic letters in the same row differ significantly $(p<0.05)$. a.p, ante partum; d p.p, day post partum; N, number; HLFI, high liver functionality index; LLFI, low liver functionality index; ${ }^{* *}$ significant at $(\mathrm{p}<0.01) ; \mathbf{N S}$, non significant

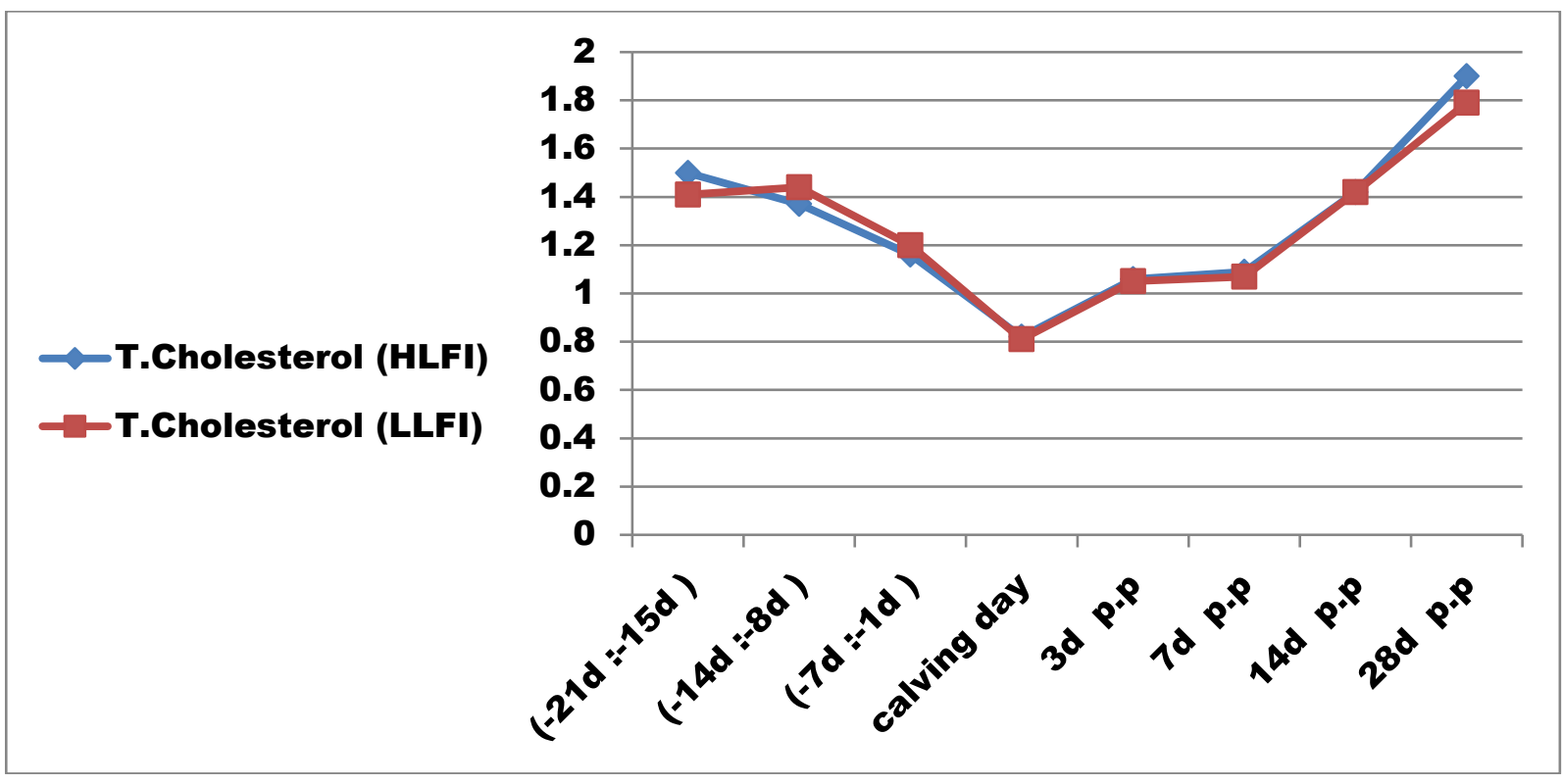

Figure 5: Serum total cholesterol concentrations in High and Low liver functionality index (LFI) groups during periparturient period. 
Table 7: Mean values of serum total bilirubin in High and Low liver functionality index groups during periparturient period.

\begin{tabular}{|c|c|c|c|c|c|c|}
\hline \multirow[b]{2}{*}{ Parameter } & \multirow[b]{2}{*}{$\begin{array}{l}\text { Days relati } \\
\text { to calving }\end{array}$} & \multirow[b]{2}{*}{$\begin{array}{l}\text { HLFI } \\
\mathrm{N}=16\end{array}$} & \multirow[b]{2}{*}{$\begin{array}{l}\text { LLFI } \\
\mathbf{N}=\mathbf{1 3}\end{array}$} & \multicolumn{3}{|c|}{$\begin{array}{c}\text { Repeated measures analysis of } \\
\text { variance }\end{array}$} \\
\hline & & & & $\begin{array}{c}\text { Index } \\
\text { (P value) }\end{array}$ & $\begin{array}{c}\text { Time } \\
\text { (P value) }\end{array}$ & $\begin{array}{c}\text { Time } \\
\mathbf{X} \\
\text { Index } \\
\text { (P value) }\end{array}$ \\
\hline \multirow{8}{*}{$\begin{array}{c}\text { Total } \\
\text { Bilirubin } \\
(\mu \mathrm{mol} / \mathrm{l})\end{array}$} & $\begin{array}{c}(-21 d:-15 d) \\
\text { a.p }\end{array}$ & $0.84 \pm 0.18^{\mathrm{d}, 4}$ & $0.89 \pm 0.25^{\mathrm{d}, \mathbf{4}}$ & \multirow{8}{*}{$\begin{array}{c}0.121 \\
\text { NS }\end{array}$} & \multirow[t]{8}{*}{$<0.0001^{* *}$} & \multirow[t]{8}{*}{$<0.0001^{* *}$} \\
\hline & $\begin{array}{c}(-14 d:-8 d) \\
\text { a.p }\end{array}$ & $0.87 \pm 0.18^{\mathbf{d}, \mathbf{4}}$ & $1.24 \pm 0.25^{\mathrm{d}, 4}$ & & & \\
\hline & $\begin{array}{c}(-7 d:-1 d) \\
\text { a.p }\end{array}$ & $1.13 \pm 0.27^{\mathrm{d}, 4}$ & $1.73 \pm 0.23^{\mathrm{d}, 4}$ & & & \\
\hline & Calving day & $3.83 \pm 0.93^{\mathrm{cd}, \mathbf{3}, \mathbf{4}}$ & $4.30 \pm 1.10^{\text {bcd, }, 2,3,4}$ & & & \\
\hline & 3 d p.p. & $2.83 \pm 0.83^{\mathrm{d}, 4}$ & $7.09 \pm 1.41^{\mathbf{a b c}, \mathbf{1 , 2 , 3}}$ & & & \\
\hline & 7 d p.p. & $4.88 \pm 2.04$ bcd,2,3,4 & $4.87 \pm 1.66^{\text {bcd,2,3,4 }}$ & & & \\
\hline & 14 d p.p. & $9.36 \pm 2.38 \quad \mathbf{a}, \mathbf{1}$ & $1.39 \pm 0.96^{\mathbf{d}, \mathbf{4}}$ & & & \\
\hline & 28 d p.p. & $8.28 \pm 2.37^{\mathbf{a b}, \mathbf{1}, \mathbf{2}}$ & $2.32 \pm 1.03^{\mathrm{d}, \mathbf{4}}$ & & & \\
\hline
\end{tabular}

Values $=$ mean \pm standard error; means of different superscript letters in the same column differ significantly $(\mathrm{p}<0.05)$. Means of different arabic letters in the same row differ significantly $(\mathrm{p}<0.05)$. a.p, ante partum; $\mathbf{d}$ p.p, day post partum; N, number; HLFI, high liver functionality index; LLFI, low liver functionality index; ${ }^{* *}$ significant at $(\mathrm{p}<0.01)$; NS, non significant

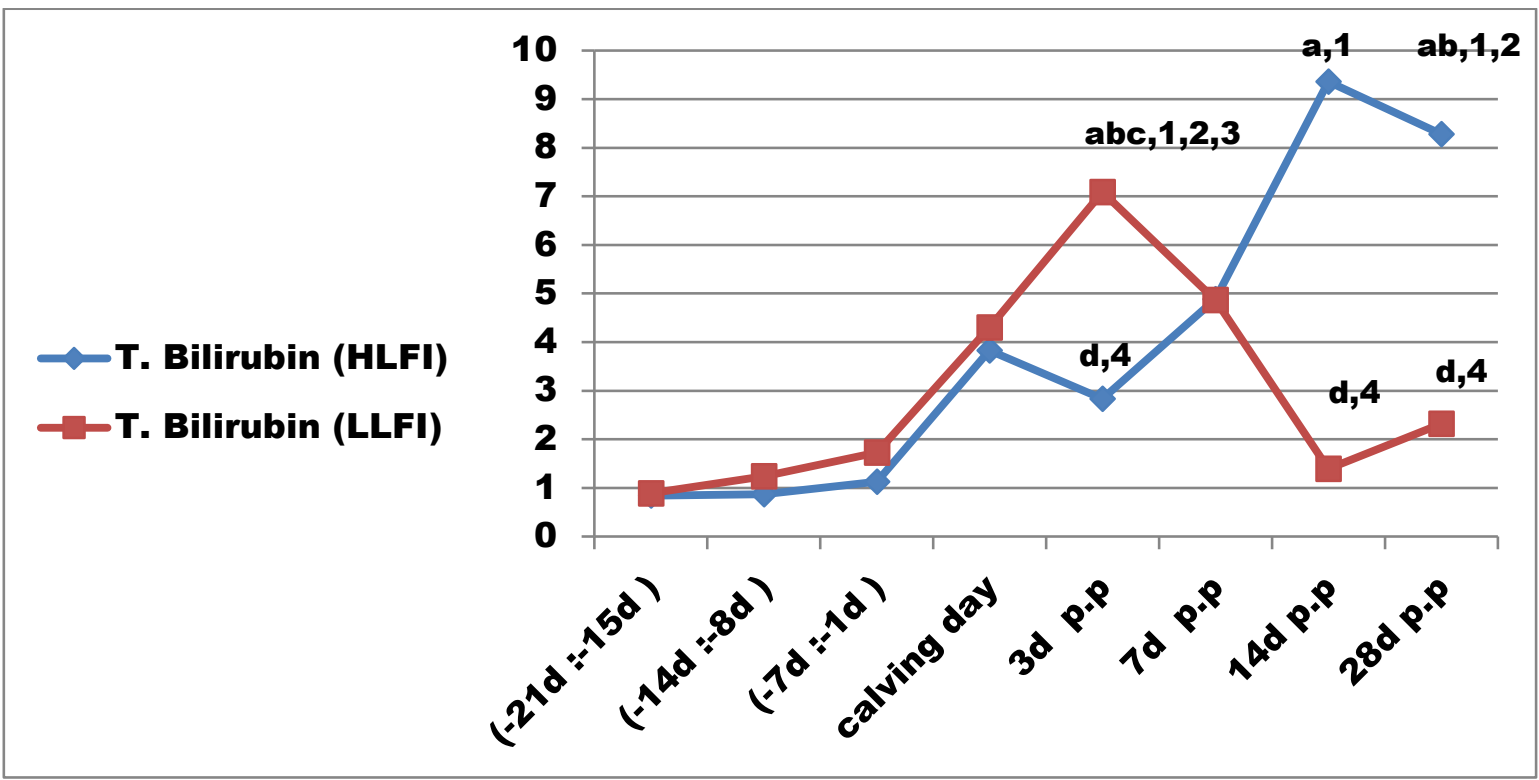

Figure 6: Serum total bilirubin concentrations in High and Low liver functionality index (LFI) groups during periparturient period. 


\section{DISCUSSION}

LAI varies between -1.5 and +1.5 points can provide a good evaluation of inflammatory phenomena and their consequences, as demonstrated by Trevisi et al. (2005) and Trevisi et al. (2010). In the present study, the individual values of LAI ranged from - 0.39 to 0.78 with a mean value $0.25 \pm 0.05$ in HLAI group and $-0.13 \pm 0.04$ in LLAI group. There was a highly significant difference $(\mathrm{p}<0.0001)$ between the high and low groups. Bertoni et al. (2008) reported that the individual values of LAI ranged from -1.51 to +1.22 , and the average levels for the quartile groups were $-0.67 \pm 0.29,-0.20 \pm 0.19,0.18 \pm 0.17$ and $0.71 \pm 0.31$ for low, intermediate low, intermediate upper and upper groups, respectively. Trevisi et al. (2013) reported that the LAI values ranged from 1.13 to +0.81 and the mean value of the -0.72 , $0.18,0.33$ and 0.62 for low, intermediate low, intermediate upper and upper groups, respectively. The average levels of LAI differed significantly $(p<0.01)$ among the quartiles.

The mean value of the LLAI in the present study was higher than those reported by Bertoni et al. (2008) and Trevisi et al. (2013). While the mean value of the HLAI in the present study was lower than those reported by Bertoni et al. (2008) and Trevisi et al. (2013). It could be attributed to species difference, LLAI group considered ideal animals, good management of the farm, number of groups as in the present study they classified into high and low groups while Bertoni et al. (2008) and Trevisi et al. (2013) classified them into four groups (low, intermediate low, intermediate upper and upper) and number of animals in each group.

The LFI varies between -12 and +5 points. Values above zero are considered favorable (Bertoni and Trevisi, 2013). In the present study, the LFI values were ranged from $(-5.13$ to 6.12$)$, the mean values of LFI differed significantly ( $\mathrm{p}<0.0001)$ among the groups. Montagner et al. (2016) reported that the LFI values were ranged from (-12 to -4$)$.

The mean values of the LFI groups in this study were higher $(-1.54 \pm 0.40$ in LLFI group and $3.35 \pm$ 0.53 in HLFI group) than those found by Trevisi et al. (2012) and Montagner et al. (2016), which were from $(-4.9 \pm 1.3$ in LLFI group and $+2.5 \pm 1.0$ in HLFI group) and (-12 to -7 in LLFI group and -7 to 4 in HLFI), respectively. The higher LFI in this study compared to Trevisi et al. (2012) and Montagner et al. (2016) may be due to high albumin values which were (45.33 g/l in HLFI and $43.36 \mathrm{~g} / \mathrm{l}$ in LLFI) compared with the results obtained by Trevisi et al. (2012) (36 g/l) and Montagner et al. (2016) which were maintained within low level in both groups (28 g/l). Montagner et al. (2016) stated that albumin which was lower in pre partum and post partum animals with LLFI may be indicative of impaired liver function (Bertoni et al., 2008), higher incidence of fatty liver (Bobe et al., 2004), and energy deficiency (Bell et al., 2000). Dann et al. (2005) stated that hypo- albuminemia is a common finding of chronic liver disease, occurring when the functional hepatic mass has been reduced to $20 \%$ or less.

\begin{abstract}
Albumin
In the present study, we noticed that there was a significant decrease $(p<0.05)$ in serum albumin in the LLAI group compared with the HLAI one at calving day, where the values were $44.51 \pm 2.08 \mathrm{~g} / \mathrm{l}$ and $48.61 \pm 1.66 \mathrm{~g} / \mathrm{l}$, respectively. This result may confirm its antioxidant role during transition period.
\end{abstract}

There was a non significant difference in serum albumin levels between the LLAI and the HLAI group during days 28, 14 and 7 P.P, while the values were (LLAI, day 28 P.P: $42.03 \pm 0.89 \mathrm{~g} / \mathrm{l}$, day 14 P.P: $42.68 \pm 1.23 \mathrm{~g} / 1$ \& day 7 P.P: $42.27 \pm 1.24 \mathrm{~g} / \mathrm{l}$ and HLAI, day 28 P.P: $43.84 \pm 1.03$ g/l, day14 P.P: $44.14 \pm 0.95 \mathrm{~g} / 1$ \& day 7 P.P: $44.70 \pm 1.57 \mathrm{~g} / \mathrm{l})$. These results weren't lined with Bertoni et al. (2008), Trevisi et al. (2010) and Trevisi et al. (2013) who noticed a significant difference between groups at the same day post partum. This result could be attributed to difference in species, season and good management of the farm.

There was a non significant difference in serum albumin levels between the LLFI and the HLFI group during day 28 P.P compared with day 3 P.P. Where the values were (LLFI, day 28 P.P: $41.35 \pm$ $0.97 \mathrm{~g} / \mathrm{l}$, day 3 P.P: $42.75 \pm 0.99 \mathrm{~g} / \mathrm{l}$ and HLFI, day 28 P.P: $44.4 \pm 0.89 \mathrm{~g} / \mathrm{l}$, day 3 P.P: $46.20 \pm 1.21 \mathrm{~g} / \mathrm{l})$. These results weren't t lined with Montagner et al. (2016) who reported that the levels of albumin were lower in LLFI pre and post partum periods than HLLFI. This is probably due to difference in species, high protein intake during this period.

\section{Total cholesterol}

Variation of serum total cholesterol in the high and the low liver activity index (LAI) showed a non significant difference in serum total cholesterol level between the LLAI and the HLAI groups at the same day post partum except at day $28 \mathrm{~d}$ P.P., There was a significant decrease $(\mathrm{P}<0.05)$ in LLAI group compared with HLAI one. Where the values were $1.72 \pm 0.09 \mathrm{mmol} / \mathrm{l}$ and $1.96 \pm 0.12 \mathrm{mmol} / \mathrm{l}$, respectively. This result was nearly similar to Bertoni et al. (2008) and Trevisi et al. (2010) who reported that there was a significant difference $(\mathrm{p}<0.05)$ between groups at the same day post partum $(7,14$ and 28) in serum total cholesterol levels. This result could be attributed to difference in 
species and individual variation to return to normal DMI.

Within each group, there was a significant decrease $(\mathrm{P}<0.05)$ in serum total cholesterol during day 3 P.P compared with day 28 P.P. in HLFI group and LLFI one. Where the values were (HLFI: day 3, $1.06 \pm$ $0.05 \mathrm{mmol} / \mathrm{l} \&$ day $28,1.90 \pm 0.13 \mathrm{mmol} / \mathrm{l})$ and (LLFI: day 3, $1.05 \pm 0.07 \mathrm{mmol} / \mathrm{l} \&$ day $28,1.79 \pm$ $0.08 \mathrm{mmol} / \mathrm{l})$.

There was a non significant difference in serum total cholesterol between the LLFI and the HLFI during the same day post partum used in calculation of index. Where the values were (LLFI: day 3, $1.05 \pm$ $0.07 \mathrm{mmol} / \mathrm{l}$ and day $28,1.79 \pm 0.08 \mathrm{mmol} / \mathrm{l}$ ) and (HLFI: day 3, $1.06 \pm 0.05 \mathrm{mmol} / \mathrm{l}$ and day $28,1.90 \pm$ $0.13 \mathrm{mmol} / \mathrm{l})$. It may be attributed to variation in species and age of the animals investigated, LLFI group considered ideal animals and good management of the farm. This result wasn't lined with Montagner et al. (2016) who reported that (LLFI: day 3, $1.75 \pm 00.15 \mathrm{mg} / \mathrm{dL}$ and day 28, 2.22 $\pm 0.15 \mathrm{mg} / \mathrm{dL}$ ) showed lower values in both times compared to (HLFI: day 3, $1.90 \pm 00.15 \mathrm{mg} / \mathrm{dL}$ and day $28,2.92 \pm 0.15 \mathrm{mg} / \mathrm{dL})$. Also, it wasn't lined with Trevisi et al. (2012) who reported that LLFI animals showed much lesser total cholesterol (lipoprotein) values and a slower post partum increase with respect to HILFI animals $(\mathrm{P}<0.001)$ for the $1^{\text {st }}$ month of lactation.

\section{Total bilirubin}

There was a highly significant difference $(p<0.01)$ in serum total bilirubin between the LLFI and the HLFI groups during the different periods.

There was a significant increase $(\mathrm{p}<0.05)$ in serum total bilirubin in the LLFI group during day 3 P.P compared with HLFI one at the same period, where the values were $7.09 \pm 1.41 \mu \mathrm{mol} / 1$ and $2.83 \pm 0.83$ $\mu \mathrm{mol} / 1$, respectively. Assenat et al. (2004) stated that the specific increase in bilirubin as a consequence of inflammation could be explained by the effect of IL-1, a proinflammatory cytokine, which inhibits the nuclear activator involved in the gene expression of key enzymes in bilirubin clearance and drug clearance in the liver. This result wasn't lined with Montagner et al. (2016) who reported that the LLFI group $(7.49 \pm 0.8 \mathrm{mg} / \mathrm{dL})$ showed lower values compared to HLFI $(9.51 \pm 0.8$ $\mathrm{mg} / \mathrm{dL}$ ) on day 3 postpartum. It could be attributed to difference in species, geographical location (Brazilian study) and climate.

There was a significant decrease $(p<0.05)$ in the LLFI group during day 28 P.P. compared with day 3 p.p., where the values were $2.32 \pm 1.03 \mu \mathrm{mol} / 1$ and $8.28 \pm 2.37 \mu \mathrm{mol} / 1$ respectively. This is probably due to LLFI group considered ideal animals when compared with previous results of other literatures and further studies needed to be done on total bilirubin at early lactation in buffaloes. This result wasn't lined with Montagner et al. (2016) who reported that on day 28 P.P, the LLFI group $(8.87 \pm$ $0.8 \mathrm{mg} / \mathrm{dL}$ ) had higher values compared to HLFI $(6.91 \pm 0.8 \mathrm{mg} / \mathrm{dL}, \mathrm{P}>0.05)$. The values obtained for bilirubin on day 3 and day 28 showed that the LLFI group had an impairment of liver functionality, because the values did not show a reduction on day 28.

There was a significant increase $(\mathrm{p}<0.05)$ in serum bilirubin in the HLFI group during day 14 P.P compared with the LLFI one at the same period, where the values were $9.36 \pm 2.38$ and $1.39 \pm 0.96$ $\mu \mathrm{mol} / 1$, respectively. Trevisi et al. (2001) reported that the impaired liver function is not synonymous with lower liver activity and the consequence of a damaged liver, but of diverted synthesis in the liver occurring during inflammation. Bilirubin values are most specific to bile flow problems than overt liver cell damage (Mostafavi et al., 2013). Van- Saun (2004b) reported that bilirubin values need to be interpreted in conjunction with total cholesterol and NEFA results to insure liver lipidosis. Further studies needed to be done on total bilirubin at early lactation in buffaloes.

Vit. A

There was a non significant decrease in serum vit. A in the low (LLAI) group compared with the high (HLAI) one except at day14 P.P., there was a significant decrease $(\mathrm{p}<0.05)$ in serum vit. A, where the mean values were $43.82 \pm 1.28 \mu \mathrm{g} / \mathrm{dl}$ and 47.17 $\pm 1.10 \mu \mathrm{g} / \mathrm{dl}$, respectively. It could be due to individual variation of animals to return to normal DMI and its antioxidant role to modulate the LLAI animal's immune system. This results in nearly similar to Bertoni et al. (2008) and Trevisi et al. (2010) who reported that there was a significant difference $(\mathrm{P}<0.05)$ between groups at the same day post partum (7, 14 and 28). The obtained results probably due to feeding ration high in protein as reported by Lindberg et al. (1999) who stated that periparturient animals fed a higher dietary $\mathrm{CP}$ ration (approximately $16 \%$ of DM) had greater serum RBP concentrations compared with animals fed a lower $\mathrm{CP}$ ration (approximately $13 \%$ of $\mathrm{DM}$ ). Because plasma albumin concentration is a sensitive indicator of protein status, the increase albumin concentrations in the present study suggested that dietary protein may be adequate during the periparturient period. Addition of multi vitamins helped to keep the animals healthy. Also, vitamin A is stored for long periods in the liver and is not as sensitive to day-to-day variation (Scherf et al., 1996). 
There was a significant increase $(\mathrm{p}<0.05)$ in serum vit A levels in both high and low (LAI) groups at days 7, 14 and 28 P.P. It may be due to increased DMI following parturition and decreased its flux toward the mammary glands as reported by (Abd Eldaim et al., 2010) who observed that retinol concentrations in milk $(43.5 \pm 6.9 \mu \mathrm{g} / \mathrm{dl}$ at 7 day after delivery), but those in colostrum were markedly higher $(295.3 \pm 5.9 \mu \mathrm{g} / \mathrm{dl})$.

\section{REFERENCES}

Abd Eldaim, M.A.; Kamikawa, A.; Soliman, M.M.; Ahmed, M.M.; Okamatsu-Ogura, Y.; Terao, A.; Miyamoto, T. and Kimura, K. (2010): Retinol binding protein 4 in dairy cows: Its presence in colostrums and alteration in plasma during fasting, inflammation, and the peripartum period. Journal of Dairy Research, 77: 27-32.

Assenat, E.; Gerbal-Chaloin, S.; Larrey, D.; Saric, J.; Fabre, J.M.; Maurel, P.; Vilarem, M.J. and Pascussi, J.M. (2004): Interleukin 1beta inhibits CAR-induced expression of hepatic genes involved in drug and bilirubin clearance. Hepatology, 40: 951-960.

Bell, A.W.; Burhans, W.S. and Overton, T.R. (2000): Protein nutrition in late pregnancy, maternal protein reserves and lactation performance in dairy cows. The Proceedings of the Nutrition Society, 59: 119-126.

Bertoni, G. and Trevisi, E. (2013): Use of the liver activity index and other metabolic variables in the assessment of metabolic health in dairy herds. The Veterinary Clinics of North America: Food Animal Practice, 29: 413431.

Bertoni, G.; Trevisi, E.; Ferrari, A.R. and Gubbiotti, $A$. (2006): The dairy cow performances can be affected by inflammations occurring around calving. Book of Abstract of the $57^{\text {th }}$ EAAP Meeting, 17-20 Antalya, Turkey, 325.

Bertoni, G.; Trevisi, E.; Han, X. and Bionaz, M. (2008): Effects of inflammatory conditions on liver activity in puerperium period and consequences for performance in dairy cows. Journal of Dairy Science, 91: 3300-3310.

Bobe, G.; Young, J.W. and Beitz, D.C. (2004): Invited review: Pathology, etiology, prevention, and treatment of fatty liver in dairy cows. Journal of Dairy Science, 87: 3105-3124.

Carr, F.H. and Price, E.A. (1926): Colour reactions attributed to vitamin A. Biochem. J. 20, 497.

Cray, C.; Zaias, J. and Altman, N.H. (2009): Acute phase response in animals: a review. Comparative Medicine, 59: 517-526.

Dann, H.M.; Morin, D.E.; Bollero, G.A.; Murphy, M.R. and Drackley, J.K. (2005): Prepartum intake, post-partum induction of ketosis and periparturient disorders affects the metabolic status of dairy cows. Journal of Dairy Science, 88: 3249-3264.

Eckersall, P.D. (2004): The time is right for acute phase protein assays. Veteinary Journal, 168: 3-5.

Gruys, E.; Toussaint, M.J.M.; Niewold, T.A. and Koopmans, S.J. (2005): Acute phase reaction and acute phase proteins. Journal of Zhejiang University Science B, 6: 1045-1056.

Lindberg, L.A.; Sinkkonen, H.; Poso, A.R.; Tesfa, A.T. and Schroder, J. (1999): Production of monoclonal antibodies and enzyme immunoassay to bovine retinol-binding protein and determination of retinol-binding protein serum levels and retinol concentrations in serum and liver in dairy cows before and after parturition. Research in Veterinary Science, 66: 259-263.

Montagner, P.; Krause, A.R.T.; Schwegler, E.; Weschenfelder, M.M.; Rabassa, V.R.; Schneider, A.; Pereira, R.A.; Brauner, C.C.; Del Pino, F.A.B.; Gonscalves, F.M. and Correa, M.N. (2016): Reduction of liver function delays resumption of postpartum ovarian activity and alters the synthesis of acute phase proteins in dairy cows.1-18.

Mostafavi, M.; Seifi, H.A.; Mohri, M. and Jamshidi, A. (2013): Optimal thresholds of metabolic indicators of hepatic lipidosis in dairy cows. Revue de Médecine Véterinaire, 164: 564571.

Murata, H.; Shimada, N. and Yoshioka, M. (2004): Current research on acute phase proteins in veterinary diagnosis: An overview. Veterinary Journal, 168: 28-40.

Rosenberger, G. (1990): Clinical Examination of Cattle. Paul Parey, Berlin/Hamburg, 2 nd Ed, 68.

SAS-Statistical Analysis System (2004): SAS User's Guide: Statitics. SAS Inst. Inc., Cary, NC; Version 9.1 for Window.

Scherf, H.; Machlin, L.J.; Frye, T.M.; Krautmann, B.A.; Williams, S.N. (1996): Vitamin E biopotency: comparison of various naturalderived and chemically synthesized atocopherols. Animal Feed Science and Technology, 59: 115-126.

Steel, R.G.D. and Torrie, J.H. 1(980): Principle and Procedures of Statistics A Biometrical Approach. $2^{\text {nd }}$ ed., McGraw-Hill Inc., New York.

Trevisi, E.; Calamari, L. and Bertoni, G. (2001): Definition of a liver activity index in the transition dairy cow and its relationship with the reproductive performance. Proceedings $X$ International Symposium of Veterinary Laboratory Diagnosticians, SalsomaggioreParma, Italy: 118-119.

Trevisi, E.; Bertoni, G.; Lombardelli, R. and Minuti, A. (2013): Relation of inflammation and liver 
function with the plasma cortisol response to ACTH in early lactating dairy cows. Journal of Dairy Science, 96: 1-11.

Trevisi, E.; Zecconi, A.; Bertoni, G. and Piccinini, $R$. (2010): Blood and milk immune and inflammatory profiles in periparturient dairy cows showing a different liver activity index. Journal of Dairy Research, 77: 310-317.

Trevisi, E.; Ferrari, A.; Piccioli-Cappelli, F.; Grossi, P. and Bertoni, G. (2010b): An additional study on the relationship between the inflammatory condition at calving time and net energy efficiency in dairy cows. In: "Energy and Protein Metabolism and Nutrition. EAAP publication No.127". Wageningen Academic Publishers. Pp: 489. 490.
Trevisi, E.; Amadori, M.; Archetti, I.; Lacetera, N. and Bertoni, G. (2011): Inflammatory response and acute phase proteins in the transition period of high-yielding dairy cows. In Veas, F. (Ed.), Acute Phase Protein - Book 2 (pp. 355-380).

Trevisi. E.; Amadori, M.; Cogrossi, S.; Razzuoli, E. and Bertoni, G. (2012): Metabolic stress and inflammatory response in high-yielding, periparturient dairy cows. Research in Veterinary Science, 93: 695-704.

Trevisi, E.; Bionaz, M. and Librandi, F. et al. (2005): Periparturient health conditions of dairy cows: metabolic effects and performances. Livestock Production Science, 98: 193.

Van- Saun, R. (2004b): 37th American Association of Bovine Practitioners, 212 pages.

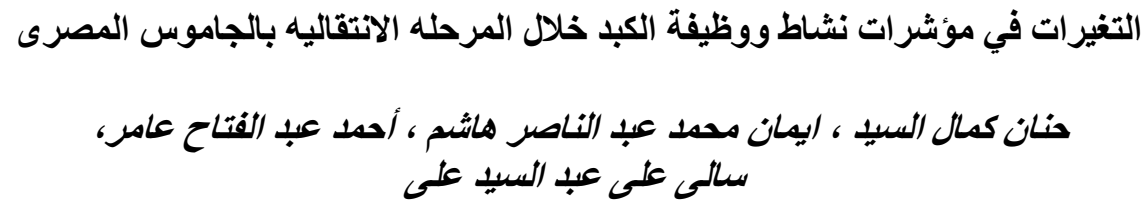

Email: hanankamal726@yahoo.com Assiut University web-site: www.aun.edu.eg

استهدفت هذه الدر اسة حساب مؤشر نشاط الكبد (LAI) ومؤشر وظائف الكبد (LFI) في الجاموس أثناء فترة ما بعد الولادة ، تم

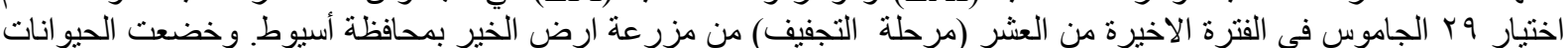

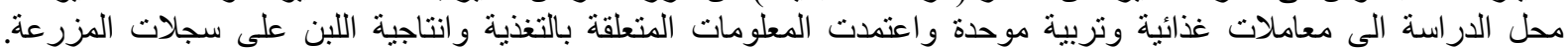

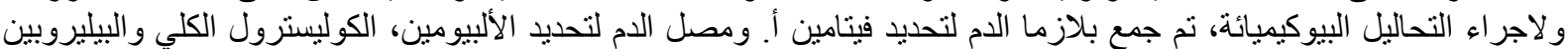

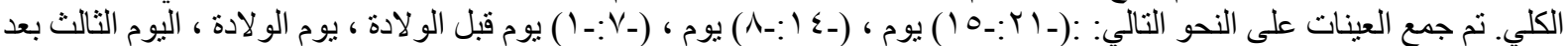

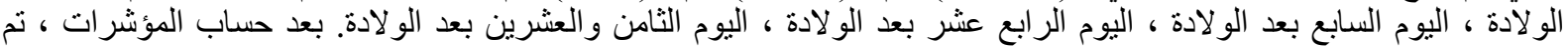

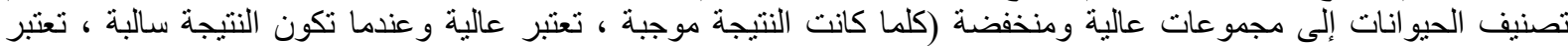

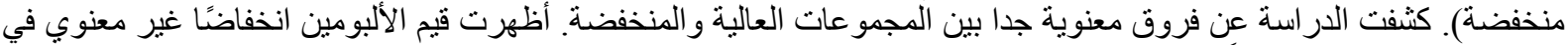

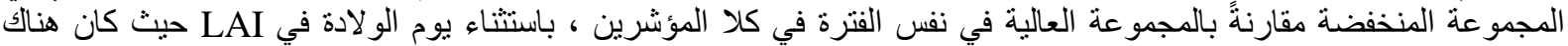

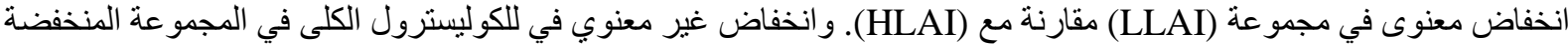

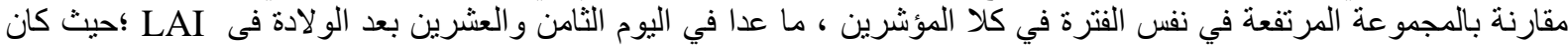

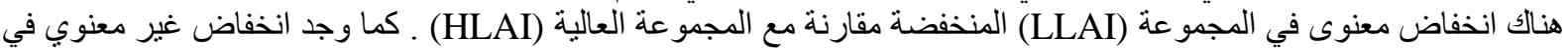

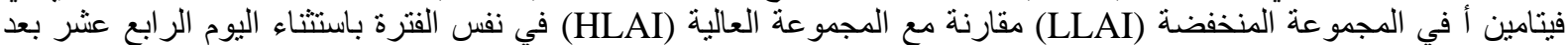

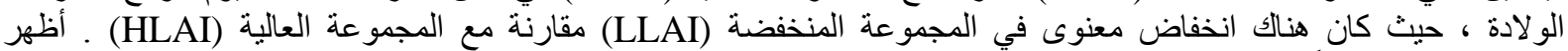

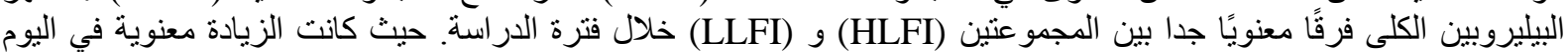

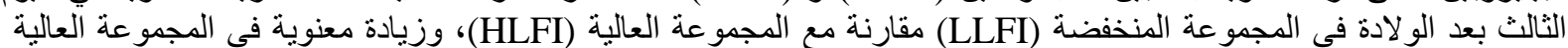

في الر ابع عشر و اليوم الثامن والعشرين بعد الولادة بالمقارنة مع المجمو عة المنخفضة (LLFI) (LLI) 